\title{
Crohn's disease - treatment with biological medication
}

\author{
Participants: \\ iD Cyrla Zaltman ${ }^{1,2}$ \\ Heda Amarante $\mathbf{1 , 2}^{\mathbf{2}}$ \\ Marta Machado Brenner ${ }^{1}$ \\ Marcia Henriques Magalhaes Costa $\mathbf{1 , 2}$ \\ Cristina Flores ${ }^{1}$ \\ Raquel Franco Leal 1,3 \\ Genoile Santana $\mathbf{1 , 2}^{\mathbf{2}}$ \\ Marco Zeroncio ${ }^{\mathbf{1 , 2}}$
}

Contact: c.zaltman@gmail.com

Final version: November 28, 2017

1. Brazilian Study Group on Inflammatory Bowel Disease, Avenida Brigadeiro Faria Lima, 2391 C) 102 - 10 Andar - Jardim Paulistano, São Paulo - SP, Brasil
2. Brazilian Gastroenterology Federation, Avenida Brigadeiro Faria Lima, 2391 C) 102 - 10 Andar - Jardim Paulistano, São Paulo - SP, Brasil
3. Brazilian Coloproctology Society, Avenida Marechal Câmara, 160 sala 916 - Centro, Rio de Janeiro - RJ, Brasil

http://dx.doi.org/10.1590/1806-9282.65.4.554

The Guidelines Project, an initiative of the Brazilian Medical Association, aims to combine information from the medical field in order to standardize producers to assist the reasoning and decision-making of doctors.

The information provided through this project must be assessed and criticized by the physician responsible for the conduct that will be adopted, depending on the conditions and the clinical status of each patient.

\section{INTRODUCTION}

Crohn's disease (CD) is characterized primarily by chronic inflammation of the gastrointestinal tract with etiology not yet fully understood. However, new knowledge about the immune system of the intestinal mucosa, especially those dependent on genetic alterations and related to the pro-inflammatory activity of TNF- $\alpha$ in the mechanism of tissue lesions, led to the development of anti-TNF $\alpha$ monoclonal antibodies. Anti-TNF $\alpha$ monoclonal antibodies, such as infliximab (IFX), adalimumab (ADA) and certolizumab (CZP), have been considered effective drugs in inducing and maintaining remission in CD. Another class of biological drugs known as anti-integrin antibodies (vedolizumab) has been introduced in clinical practice. Vedolizumab is an $\alpha 4 \beta 7$ integrin inhibitor and blocks the migration of leukocytes through the intestinal endothelium. Ustekinumab (UTQ) is a humanized monoclonal antibody directed against the common p40 subunit of interleukin (IL) -12 and IL-
23, two important pro-inflammatory cytokines in the pathophysiology of CD.

\section{METHOD}

The objective of this guideline is to provide recommendations, which may assist in the decision making, in relation to patients with Crohn's Disease, regarding the therapeutic role of biological drugs. For this, a systematic review of the literature was carried out, with descriptors according to the PICO ${ }^{1,2}$ : Crohn's disease, monoclonal anti-TNF $\alpha$, infliximab (IFX), adalimumab (ADA), certolizumab (CZP), anti-integrin antibodies (vedolizumab), ustekinumab (UTQ), benefit, damage. Carried out without restriction of period, in the MEDLINE database, with the strategy: (Crohn Disease OR Crohn's Enteritis OR Regional Enteritis OR Crohn's Disease OR Crohns Disease OR Inflammatory Bowel Disease 1 OR Gran- 
ulomatous Enteritis OR Granulomatous Colitis OR Terminal Ileitis OR Regional Ileitis) AND (Antibodies, Monoclonal OR Tumor Necrosis Factor-alpha OR Interferon-alpha OR Leukocyte Interferon OR alpha Interferon) AND Random*. 575 studies were found, of which 45 were selected to answer the clinical question: What is the role (benefit and harm) of biological drugs in the treatment of Crohn's Disease? The degree of recommendation to be used stems directly from the available strength of the studies included according to Oxford ${ }^{50}$, and the use of the GRADE sys$\mathrm{tem}^{48}$.

\section{RESULTS}

Anti-tnf- $\alpha$ biological therapy

Infliximab

IFX is an anti-TNF- $\alpha$ composed of the binding of variable regions of murine monoclonal antibody binding specific for human tumor necrosis factor (A2) to the constant regions of human IgG1 immunoglobulin.

\section{Remission induction}

The first study (multicenter, double-blind) published with IFX in patients $(\mathrm{N}=108)$ with moderate to severe CD refractory to 5-ASA and steroids was done in 1997, showing that the drug was effective when compared to placebo in infusion at a dose of $5 \mathrm{mg}$, $10 \mathrm{mg}$ or $20 \mathrm{mg} / \mathrm{kg}$, with no difference in results between these doses. Comparing IFX with placebo, up to four weeks, the clinical response rate was $64 \%$ in patients treated with $5-20 \mathrm{mg} / \mathrm{kg}$ IFX vrs. $17 \%$ [NNT $=1.6])$ and the remission was 33 vs. $4 \%(\mathrm{NNT}=4)$, respectively. Adverse effects rates (AEs) were similar in the groups ${ }^{3}(\mathbf{B})$.

In 1999, authors demonstrated that infusions of IFX ( $5 \mathrm{mg} / \mathrm{kg}$ [n = 31] and $10 \mathrm{mg} / \mathrm{kg}[\mathrm{n}=32])$ at weeks 0,2 and 6 were superior to placebo $(n=31)$ at the closure of fistulas (abdominal or perianal) at a follow-up of 18 weeks. The number of patients with $\geq 50 \%$ reduction in the number of active drainage fistulas was $62 \%$ in the IFX group $(5-10 \mathrm{mg} / \mathrm{kg}$ ) versus $26 \%$ in the placebo group (NNT = 3). The apparent cure was followed by abscess formation in $11 \%$ of patients treated with IFX due to occlusion of the fistulous orifice in the cutaneous plane, with maintenance of its opening in the gastrointestinal tract. The most common AEs with IFX were headache, abscess, upper respiratory tract infection and fatigue $\mathbf{4}(\mathbf{B})$.

\section{Remission maintenance}

One of the main studies using IFX as an effective drug in the maintenance of remission was the randomized clinical trial (RCT) ACCENT I (Crohn's Disease Clinical Trial Evaluating Infliximab in a New LongTerm Treatment Regimen in Patients with Fistulizing Crohn's Disease), multicenter and double-blind study, which included 573 patients with luminal CD (CDAI between 220 and 400) who received IFX (5.0 mg/kg IV) and were evaluated for response at the end of two weeks. At this stage, $58 \%$ of the patients responded to this first dose with a reduction of 70 points in the CDAI from the baseline value and reduction of at least 25\% in the total score. Patients who responded to IFX were randomized into three groups: group I - placebo intravenous infusions at weeks 2 and 6 and every 8 weeks until week 46; group II: $5.0 \mathrm{mg} / \mathrm{kg}$ IFX at these same intervals and group III: $5.0 \mathrm{mg} / \mathrm{kg}$ IFX at weeks 2 and 6 followed by $10 \mathrm{mg} / \mathrm{kg}$ every eight weeks until the end of follow-up $5(\mathbf{B})$. At the $30^{\text {th }}$ week, $39 \%$ of the patients in group II were in clinical remission with CDAI of less than 150; $45 \%$ in group III and $21 \%$ in group I, this difference being significant $(\mathrm{ARR}=0.18$ with $95 \%$ CI: 0.05 to 0.277 and NNT $=5$ when comparing group I and II and ARR = 0.23 with 95\% CI: 0.106 to 0.354 and NNT = 4 comparing groups I and III, respectively). After week 54, $40 \%$ of the IFX group achieved clinical remission with corticosteroid withdrawal versus $15 \%$ of the placebo group, with no significant differences between the two doses of 5 or $10 \mathrm{mg} / \mathrm{kg}$.

The incidence of severe infections was similar in all treatment groups $\mathbf{6}^{\mathbf{6}}(\mathbf{B})$.

Aiming at analyzing IFX behavior on fistulizing $\mathrm{CD}$, a multicenter, double-blind, randomized, placebo-controlled study (ACCENT II, 2004) evaluated the efficacy of IFX maintenance therapy in 306 adult patients with CD and one or more fistulas, with active drainage, abdominal or perianal, of at least three months duration. Patients received IFX $5 \mathrm{mg} / \mathrm{kg}$ intravenously at weeks 0,2 and 6 .

A total of 195 patients who had a response at weeks 10 and 14, as well as 87 unresponsive patients were then randomized to receive placebo or IFX $5 \mathrm{mg} / \mathrm{kg}$ IV every 8 weeks (at weeks 14, 22, 30, 38 and 46) were then followed up to week 54. Among responders, response loss time was significantly longer for patients receiving IFX maintenance therapy than for those receiving placebo maintenance $(>40$ weeks vs. 14 weeks, $p<0.001$ ); $42 \%$ versus $62 \%$ lost the response $(\mathrm{NNT}=5)$. Among the non-responders 
in the IFX vs. placebo comparison, $21 \%$ and $16 \%$ had subsequent response, respectively, but without statistical significance $(p=0.6)$. IFX did not reduce the risk of new fistula-related abscess in 54 weeks (ARR $=5.1 \%, 95 \%$ CI -0.32 to 0.13 , NNT $=$ NS). It should be noted that in this study patients were mixed with abdominal and perianal fistulas, compromising the analysis of the results. Patients in the IFX maintenance group were more than twice as likely to have antinuclear antibodies and almost four times as likely to have antibodies to double-stranded DNA than placebo maintenance patients. There was no difference in the number of patients with adverse effects between the two groups $(\mathrm{NNT}=\mathrm{NS})^{7}(\mathbf{B})$.

\section{Infliximab in combined therapy}

In the double-blind RCT SONIC study, the efficacy of IFX monotherapy with azathioprine monotherapy (AZA) and the two combined drugs was evaluated in 508 adult patients with moderate to severe CD and who were not exposed to previous immunosuppressive or biological therapy. Patients were randomly assigned to receive an intravenous IFX $5 \mathrm{mg} / \mathrm{kg}$ infusion at weeks 0,2 and 6 and then every 8 weeks plus daily placebo capsules; oral AZA $2.5 \mathrm{mg} / \mathrm{kg} /$ day, plus a placebo infusion; or combination therapy with the two drugs. Patients were given study medication by the $30^{\text {th }}$ week and could continue in a blind extension up to the $50^{\text {th }}$ week. Combination therapy (IFX with AZA) was superior to IFX monotherapy for induction of corticosteroid-free remission at week 26 (57\% vs. 45\%, respectively, $\mathrm{p}<0.05, \mathrm{NNT}=4$ to 55). AZA monotherapy was the least effective therapy (30\% corticosteroid-free remission at week 26, $\mathrm{p}<0.01 \mathrm{vs.} \mathrm{both} \mathrm{IFX-based} \mathrm{regi-}$ mens). Mucosal healing (defined as the disappearance of ulcers) was higher in the combined treatment group (AZA with IFX) compared to the other two groups. There were severe infections in $3.9 \%$ of patients in the combination therapy group, $4.9 \%$ in the IFX group and $5.6 \%$ in the AZA group (there is no statistical significance for any of the comparisons, NNT $=$ NS) $)^{8,9}(A)$.

A network meta-analysis confirms that IFX or the combination of IFX and AZA are more effective than placebo in inducing remission in $\mathrm{CD}$ in adult patients ${ }^{10}(\mathrm{~A})$.

In another study, 113 adult patients with moderate to severe (CDAI between 220 and 400) corticosteroid dependent (luminal relapse with reduction of corticosteroids for at least two times) were randomized to IFX $5 \mathrm{mg} / \mathrm{kg}$ or placebo with infusion at weeks 0 ,
2 and 6 . All patients received AZA $2-3 \mathrm{mg} / \mathrm{kg} /$ day or 6 mercaptopurine (6-MP) $1-1.5 \mathrm{mg} / \mathrm{kg} /$ day. Clinical success (remission, without the use of corticosteroids) was defined as CDAI $<150$ without corticosteroids. At the $24^{\text {th }}$ week, there was benefit with an increase in the clinical remission rate for the combination therapy group (ARA $=27.5 \%, 95 \%$ CI: $-44 \%$ to $-10 \%$, NNH $=4)^{11}(\mathrm{~A})$.

Early treatment (top-down strategy) with IFX was compared with a standard approach (corticosteroids + immunomodulators, step-up strategy) in a multicenter, open-label RCT. A total of 133 adult patients with active CD (CDAI score $>200$ points for a minimum of 2 weeks prior to randomization) of recent onset (without prior therapy with corticosteroids, antimetabolites or IFX) were randomly assigned to two groups: initial therapy with IFX and AZA, without initial therapy with corticosteroids and then AZA. Further treatment with IFX and, if necessary, corticosteroids were allowed to control disease activity. Although remission rates at 1 year were similar (77\% vs. 64\%, respectively, $p=0.15$ ), $19 \%$ in the step-up strategy were still corticosteroid compared to $0 \%$ in the top-down approach $(\mathrm{p}<0.001)$. Endoscopic healing was greater using the top-down approach. There was no difference between the two groups in terms of the number of serious adverse events ${ }^{12}(\mathrm{~A})$.

\section{Infliximab in preventing postoperative clinical} recurrence

A multicenter, placebo-controlled RCT, evaluated the efficacy of IFX in preventing postoperative recurrence in CD in 297 adult patients (mean age 36 years) treated with ileocolic resection within 45 days (mean of 36 days) prior to randomization, to IFX $5 \mathrm{mg} / \mathrm{kg}$ infused every 8 weeks versus placebo for 208 weeks. IFX was not superior to placebo to prevent clinical recurrence at week 76 , but was able to reduce endoscopic recurrence. A lower proportion of patients in the IFX group had a clinical recurrence (CDAI $\geq 200$ and $\geq 70$ baseline increase points, as well as endoscopic recurrence defined as Rutgeerts $\geq \mathrm{i} 2$ score or appearance of new fistula or return of drainage, or abscess) up to week 76, compared to the placebo group, but this difference was not statistically significant (12.9\% vs. $20.0 \%$; absolute risk reduction [ARR] with IFX, 7.1\%; (95\% CI: $-1.3 \%$ to $15.5 \%$; $p=0.97)$. A significantly lower proportion of patients in the IFX group had endoscopic recurrence compared to the placebo group (30.6\% vs. 60.0\%; RRA with IFX, 29.4\%, 95\% CI: 
$18.6 \%$ to $40.2 \%$; NT $=4 ; \mathrm{p}<0.001$ ). In addition, a significantly lower proportion of patients in the IFX group had endoscopic recurrence based only on the scores of Rutgeerts $\mathbf{5}(\mathbf{B}) \geq \mathbf{i}_{2}(22.4 \%$ vs $51.3 \%$, RRA with IFX, $28.9 \%$, 95\% CI: $18.4 \%$ to $39.4 \%, p<0.001)$. This RCT was interrupted early (104 weeks) because there was no difference in the primary outcome (clinical recurrence), but this rule was not pre-established ${ }^{13}(\mathbf{A})$.

\section{RECOMMENDATIONS}

\section{Infliximab}

It is effective in inducing and maintaining remission of Crohn's disease in patients with moderate to severe refractory to conventional therapy (B).

It presents efficacy in fistulizing CD (B).

It is effective in preventing recurrence of Crohn's disease in patients undergoing ileocolectomy (A).

Combination therapy with azathioprine promotes better clinical outcomes when compared to infliximab or azathioprine monotherapy (A).

\section{Adalimumab}

Adalimumab (ADA) is a fully human recombinant IgG1 monoclonal antibody that binds to soluble TNF- $\alpha$.

\section{Adalimumab in remission induction}

The first double-blind, placebo-controlled RCT published with ADA for patients with CD the CLASSIC I study (2006). A total of 299 patients (18-75 years) with moderate to severe CD (CDAI 220-450) were randomized into 4 groups and followed up for 4 weeks: subcutaneous placebo (SC) at week 0 and at week 2; ADA $40 \mathrm{mg}$ at week 0 and $20 \mathrm{mg}$ at week 2; ADA $80 \mathrm{mg}$ at week 0 and 40mg at week 2; and ADA 160mg at week 0 and $80 \mathrm{mg}$ at week 2.284 patients (95\%) completed the study and comparing placebo vs. initial ADA dose of $40 \mathrm{mg}$ vs. $80 \mathrm{mg}$ vs. $160 \mathrm{mg}$, the study showed: remission rate (CDAI score $<150$ ) up to 4 weeks was $12 \%$ vs. $18 \%$ (not significant) vs. $24 \%(p=0.06)$ vs. $36 \%(p=$ 0.001 , NNT $=5$ ); reduction in CDAI score $\geq 100$ points up to 4 weeks occurred in $25 \%$ vs. $34 \%$ vs. $40 \%$ vs. $50 \%$ $(\mathrm{p}<0.05$, NNT $=4)$. The incidence of adverse events was similar between groups except for the presence of an injection site reaction when ADA 160/80 mg dose was used. Therefore, the 160/80mg dose of ADA SC had higher rates of clinical remission and improvement of symptoms when compared to the other doses and placebo (ideal dose in induction of remission) ${ }^{14}(\mathrm{~A})$.
The GAIN study (2007) evaluated the use of ADA as an induction therapy in patients $(\mathrm{n}=325)$ with moderate to severe CD (CDAI between 220 and 450) who had either a loss of response or who were intolerant to IFX treatment. Patients were randomized to ADA SC treatment at doses of $160 / 80 \mathrm{mg}$ or placebo at weeks 0 and 2. 301 patients (93\%) completed the study and at week $4,21 \%$ of patients ( 34 of 159 ) randomized to ADA had clinical remission (CDAI <150) compared to 7\% $(12$ of 166) of those treated with placebo, this difference being significant (ARA $=14.2 \%, 95 \%$ CI: -0.217 to -0.067 and NNT $=7$ ). There were fewer adverse events in the $\mathrm{ADA}$ group $(\mathrm{ARR}=15.7 \%, 95 \% \mathrm{CI} 0.05$ to 0.26 , NNT = $6)$ and there was no difference in the risk of infection between ADA vs. placebo $(\mathrm{NNT}=\mathrm{NS})^{15}(\mathbf{B})$.

\section{Adalimumab in remission maintenance}

The CLASSIC II study was conducted, including 55 patients who were in clinical remission at the end of the CLASSIC I study, to establish the ADA's efficacy in maintaining the treatment of patients with CD. Patients were eligible for CLASSIC II randomization if they were in clinical remission at week 0 (week 4 in CLASSIC I) and week 4 . At week 4 , those in remission were randomized to receive maintenance treatment via subcutaneous ADA $40 \mathrm{mg}$ every two weeks, ADA $40 \mathrm{mg}$ weekly or placebo from week 4 to week 55 . Patients who were not in remission at both times entered into an open cohort and received $40 \mathrm{mg}$ every two weeks. All patients were followed until the end of week 56 . Clinical remission at the end of 56 weeks occurred in $79 \%(15 / 19)$ in the ADA group treated on alternate weeks, 83\% (15/18) in the ADA group treated weekly and $44 \%(8 / 18)$ in the ADA group who received the placebo; $p<0.05$ for each ADA group versus placebo. Among the patients who were not randomized, $46 \%$ were in remission at the $56^{\text {th }}$ week $^{6}(B)$.

Maintenance treatment with ADA was well tolerated. Rates of serious adverse events were low in ADA-treated patients and were similar to placebo. No patient developed severe infectious adverse events, opportunistic infections, tuberculosis, lupus, demyelinating neurological diseases or lymphoma; and no patient $\operatorname{died}^{16}(\mathbf{B})$.

The double-blind, multicenter RCT CHARM established ADA efficacy for patients with moderate to severe luminal and fistulizing CD (CDAI between 220 and 450) for at least 4 months at a follow-up of 56 weeks. Participants had ADA induction therapy (80 $\mathrm{mg}$ at week 0 and $40 \mathrm{mg}$ at week 2) and at week 4 , 
patients were stratified by response (CDAI decrease $>70$ points from the baseline) and randomized to 1 of 3 groups: ADA 40mg weekly, ADA 40mg every 2 weeks and a third with placebo. If patients had no response or had relapses after week 12, they could switch to open treatment with ADA. The primary outcome evaluated was the percentage of randomized responders who achieved clinical remission (CDAI <150) at weeks 26 and 56. The percentage of randomized responders in remission was significantly higher in ADA $40 \mathrm{mg}$ weekly and $40 \mathrm{mg}$ weekly at week 2 versus placebo at week 26 (40\%, $47 \%$ and $17 \%$, respectively, $\mathrm{p}<0.001)$ and at week 56 (36\%, $41 \%$ and $12 \%$, respectively, $\mathrm{p}<0.001)$. In the $26^{\text {th }}$ week, it was possible to find an increase in remission compared to placebo, for both ADA in alternate weeks and weekly $(\mathrm{ARA}=25.8 \%$ with $95 \%$ CI: 0.150 to 0.36 and NNT $=$ 4 and ARA $=27.8 \%$ with $95 \%$ CI: 0.167 to 0.380 and $\mathrm{NNT}=3$, respectively). In the 56-week evaluation, there was no difference between ADA treatment in alternate weeks or weekly. However, remission in ADA-treated patient groups remained greater than that in the placebo group (ARA $=25.4 \%$ with $95 \% \mathrm{CI}$ : 0.154 to 0.343 and NNT $=4$ and ARA $=31.4$ with $95 \%$ CI: 0.209 to 0.407 and NNT $=3$, respectively) $)^{17}(\mathbf{B})$.

This study also showed that patients who were virgins of biological therapy responded more (remission rate) to ADA than those with previous IFX use compared with placebo (ARA $=30.6 \%$ CI 95\% -0.41 to -0.19 ; NNT $=3$ ). The subgroup of patients who presented previous failure to the IFX obtained better response (remission rate) to ADA compared to placebo $(\mathrm{ARA}=20.5 \%, 95 \% \mathrm{CI}-0.31$ to $-0.09, \mathrm{NNT}=5)$. Adverse events occurred in $59 \%$ of the patients (507 out of 854) during the induction period; however, only $5.3 \%$ of the cases manifested in the severe form, with a case of multiple sclerosis ${ }^{17}(\mathbf{B})$.

After 56 weeks in the CHARM study, patients entered into an open-label study (ADHERE - Additional long-term Dosing with Humira to Evaluate Sustained Remission and Efficacy in CD). Patients still receiving blind therapy at the end of the study CHARM received ADA 40 mg every two weeks after entry into ADHERE. Patients with ADA open-label therapy every 2 weeks or weekly continued on the same regimen. During ADHERE, patients with ADA every 2 weeks could be switched to weekly doses in the case of relapse or non-response of the disease. Almost half of the participants had previous treatment with another TNF inhibitor. Remission was defined as a CDAI score be- low 150. Among the 382 patients who completed the study, clinical remission rates at 2 years (according to original randomization) were $37.6 \%$ in randomized to placebo, $41.9 \%$ with ADA every two weeks, and $49.8 \%$ with ADA once a week. In addition, it was possible to verify reduction in the rate of hospitalizations and the need for surgical treatment, associated to the improvement of quality of life ${ }^{18}(\mathbf{B})$.

Long-term results from the CHARM and ADHERE trials suggest that by continuing ADA treatment for 4 years, less than one third of people maintain remission; the same proportion of people may stop treatment due to adverse events ${ }^{19}(\mathbf{B})$.

The effectiveness of ADA in maintenance was proven in the CHARM ${ }^{17}(\mathbf{B})$ study, with some interesting data on mucosal healing available in the EXTEND study (Extend the Safety and Efficacy of Adalimumab Through Endoscopic Healing [double-blind RCT]), which included 135 patients aged 18-75 years with active ileocolic CD, moderate to severe for $\geq 4$ months who were treated on an ADA induction regimen at a dose of $160 \mathrm{mg}$ SC at week 0 and then $80 \mathrm{mg}$ at week 2 . At week 4 , patients $(n=129)$ were randomized into $40 \mathrm{mg}$ ADA or placebo every two weeks until week 52. ADA use without blinding was given to patients with relapsed or unresponsive patients, starting at week 8 . The healing of the mucosa was reevaluated by ileocolonoscopy at weeks 12 and 52. At week 12 the ADA versus placebo comparison showed: clinical remission (CDAI <150) in 47\% vs 28\% ( $=0.021$, NNT = 6); remission (based on Crohn's Disease Endoscopic Index of Severity $)$ in 52 vs. $28 \%(p=0.006$, NNT = 5) and mucosal healing (based on ileocolonoscopy) in 27 vs. $13 \%$ $(p=0.056)$. This comparison at week 52 resulted in: clinical remission in $33 \%$ vs. $9 \%(p=0.001$, NNT 5); remission in $28 \%$ vs. $3 \%$ ( $<<0.001$, NNT 4$)$ and mucosal healing in 24 vs. $0 \%(p<0.001$, NNT5). Therefore, ADA maintenance therapy immediately after ADA induction may increase remission rates (based on Crohn's Disease Endoscopic Index of Severity) at 12 and 52 weeks in patients with active $\mathrm{CD}^{20}(\mathbf{B})$. At 52 weeks, there was a lower hospitalization rate in patients who maintained the healed mucosa. In this study, ADA was associated with 5 severe adverse events, including 3 opportunistic infections ${ }^{20}(\mathbf{B})$.

\section{Adalimumab in fistulizing disease}

In the CHARM study, the results of 117 patients (70 ADA [combined group] and 47 placebo) with CD fistulas, $2 / 3$ of them with single lesion and $1 / 3$ with 
more than one path were analyzed. At week 26, 30\% of ADA maintenance patients (combined groups) had complete fistula closure, increasing to $33 \%$ at week 56 , versus $13 \%$ in the placebo group (ADA vs placebo at weeks 26 and 56 with significant difference, $\mathrm{p}=$ 0.43 and $p=0.016$, respectively $)^{(17)}(\mathbf{A})$.

An extension of the CHARM (open-label extension) study, evaluating long-term results, with an approximate 2-year follow-up, showed that $60 \%$ (22/37) of ADA-treated patients maintained healing of fistulas, although non responders, for withdrawal (loss of efficacy, adverse effects, protocol violation), have reached the significant mark of $31 \%^{21}(\mathbf{B})$.

In the GAIN study described above, in the 325 included patients, 45 had perianal fistulas and no differences were identified for the clinical response or remission of the lesions, with the induction regimen 160/80mg at weeks 0 and 2 and placebo ${ }^{15}(\mathbf{B})$.

With the same posology and control scheme in 4 weeks, another multicenter, prospective, open, observational study, including patients who had already used and dispensed IFX for the same reasons, of the 22 patients with fistulizing disease, five (23\%) experienced remission of fistula (complete closure of all fistulae that were draining at the baseline), and nine (41\%) experienced improvement of the fistula ( $\geq 50 \%$ decrease in the number of fistulas that were draining at baseline) at week $4^{22}(\mathrm{C})$.

The open-label, single-arm, multicenter, phase IIIb CHOICE study evaluated the safety and efficacy of ADA in patients with moderate to severe CD who did not respond or had lost the response to IFX. Of the 88 patients with at least one fistula with baseline drainage, 83 had data available at the last visit (the last visit dates ranged from week 4 to week 36). Fistula drainage decreased by $41.3 \%$ at the last visit compared to the baseline, at which time approximately $40 \%$ of the patients (34 out of 88 patients) had complete cure of the fistula ${ }^{23}(\mathbf{C})$.

\section{Adalimumab in combined therapy}

A multicenter, open-label RCT DIAMOND - Deep Remission of Immunomodulator and Adalimumab Combination Therapy for Crohn's Disease) evaluated the efficacy of ADA with and without azathioprine in patients $(\mathrm{N}=177)$ with active, moderate to severe CD (CDAI $\geq 220$ ), virgin to biological and immunomodulators (AZA, 6-MP, methotrexate, tacrolimus, or cyclosporine). Patients were randomized to SC administration of ADA at $160 \mathrm{mg}$ at week $0,80 \mathrm{mg}$ at week 2 , and thereafter at $40 \mathrm{mg}$ every 2 weeks up to 52 weeks (monotherapy group, $\mathrm{n}=92$ ), or ADA with AZA (25-100 mg per day) (combined group, $n$ $=85$ ) for 52 weeks. The primary outcome analyzed was clinical remission $(\mathrm{CDAI}<150)$ at week 26 . Intent-to-treat analysis with non-responder imputation (NRI) showed that the clinical remission rate at week 26 was not different between the monotherapy group and the combined group $(71.8 \%$ vs. $68.1 \%$, OR $=0.84,95 \%$ CI 0.44 to $1.61, p=0.63)$. The analysis by protocol also showed no difference between the two groups for this outcome. The rate of endoscopic improvement at week 26 was significantly higher in the combined group (84.2\%) than in the monotherapy group $(63.8 \%, p=0.019)$. However, these rates at week 52 were not significantly different between the two groups $(79.6 \% \text { versus } 69.8 \%, p=0.36)^{24}(\mathbf{A})$.

During the 52 weeks, adverse events occurred that excluded the study in 19 patients (22.3\%) in the monotherapy group and in 22 patients $(24.2 \%)$ in the combined group. The incidence of adverse events was not different between the two groups. Therefore, this study suggests that AZA does not contribute to improving the efficacy of ADA treatment, as opposed to its contribution to the additional efficacy of treatment with $\operatorname{IFX}^{24}(\mathbf{A})$.

\section{Adalimumab in the prevention of post-opera-} tive recurrence

Patients ( $\mathrm{N}=51$ ) with $\mathrm{CD}$ and undergoing ileocolic resection were randomized to treatment with ADA SC 160/80mg and maintenance with 40mg every two weeks, AZA PO $2.0 \mathrm{mg} / \mathrm{kg} /$ day or mesalazine PO $3.0 \mathrm{~g} /$ day, starting 2 weeks after surgery and with follow-up for 2 years. After two years, $6.3 \%$ of the individuals randomized to ADA treatment had endoscopic recurrence compared to $64.7 \%$ and $83.3 \%$ of those randomized to treatment with AZA and mesalazine, respectively, these differences being significant and favoring individuals treated with $\mathrm{ADA}$ (RRA $=0.585$ with $95 \% \mathrm{CI}$ : 0.207 to 0.699 and NNT $=2$ and RRA $=0.771$ with $95 \%$ CI: 0.407 to 0.8883 and NNT $=1$, for ADA treatment compared to AZA and mesalazine respectively ${ }^{25}(\mathbf{B})$. Regarding clinical data, $12.5 \%$ of ADA-treated patients presented clinical recurrence compared to $64.7 \%$ and $50 \%$ of those treated with AZA and mesalazine, respectively, with significant differences (RRA $=0.522$ with 95\% CI: 0.132 to 0.719 and NNT $=2$ and RRA $=$ 0.375 with $95 \%$ CI: 0.001 to 0.568 and NNT $=3$, for ADA treatment compared to the use of AZA and me- 
salazine, respectively $)^{25}(\mathbf{B})$. Therefore, in patients with $\mathrm{CD}, \mathrm{ADA}$ is superior to thiopurines and mesalazine in preventing recurrence of postoperative disease.

\section{RECOMMENDATIONS:}

\section{Adalimumab}

It is effective in inducing and maintaining remission of Crohn's disease in patients with moderate to severe activity refractory to conventional therapy (B).

May be effective in fistulizing Crohn's disease (B).

It is effective in preventing recurrence of Crohn's disease in patients undergoing ileocolectomy (B).

There is no evidence of clinical benefit in the combination of adalimumab with azathioprine in patients with moderate to severe Crohn's disease (A).

\section{Certolizumab pegol}

Certolizumab pegol (CZP) is composed of TNF-alpha inhibitor humanized monoclonal antibody fragment expressed in Escherichia coli and conjugated to two polyethylene glycol (PEG) molecules, for subcutaneous administration. CZP, unlike the other anti-TNFs, does not contain the Fc portion of the immunoglobulin and thus does not induce complement activation, antibody-dependent cytotoxicity, and apoptosis. Also, because it is not an IgG1 immunoglobulin, as in the case of the other anti-TNFs, it does not cross the placental barrier ${ }^{26,27}(\mathbf{A})$.

Certolizumab pegol (CZP) is a Fab' fragment of a humanized antibody recombined against tumor necrosis factor alpha (TNF- $\alpha$ ).

\section{Certolizumab pegol in remission induction}

A multicenter, double-blind placebo-controlled RCT study evaluated the efficacy of therapy with CZP in 439 adults (18-75 years) with moderate to severe CD (CDAI 220- 450) without previous anti-TNF therapy. There was stratification according to serum C-reactive protein (CRP) concentration at baseline $(<10 \mathrm{mg} / \mathrm{L}, \geq 10 \mathrm{mg} / \mathrm{L})$. Patients $(\mathrm{N}=439)$ were randomized to receive CZP (400 mg subcutaneously, $\mathrm{n}=$ $223)$ or placebo $(n=215)$ at weeks 0,2 and 4 . The primary outcome evaluated was clinical remission rates (CDAI $\leq 150$ points) at week 6 . The clinical response (reduction $\geq 100$ points of CDAI score at week 0 ) at weeks 2,4 , and 6 was considered a secondary outcome. There was no difference in the rate of patients in clinical remission at week 6 between the CZP vs. placebo groups $(p=0.174 ; \mathrm{NNT}=\mathrm{NS})$, as well as in the clinical response rate $(p=0.179 ;$ NNT $=$ NS). Serious adverse events occurred in $5 \%$ and $4 \%$ of patients in the CZP and placebo groups, respectively ${ }^{28}(\mathbf{A})$.

In the PRECiSE 1 (Pegylated Antibody Fragment Evaluation in Crohn's Disease: Safety and Efficacy 1) study, a multicenter, double-blind, placebo-controlled RCT it was included adult patients $(\mathrm{N}=662)$ with active, moderate to severe CD (CDAI between 220 and 450) without control of the disease for at least three months, on the use of corticosteroids or immunosuppressants or association of both drugs. These patients were randomized to treatment with CZP SC $400 \mathrm{mg}$ or placebo at weeks 0, 2 and 4 and every 4 weeks to 24 weeks with evaluations between $6^{\text {th }}$ and $26^{\text {th }}$ weeks ${ }^{28}(\mathbf{A})$. With the objective of analyzing a clinical response, defined as a reduction greater than 100 points in baseline CDAI and clinical remission rate $(\mathrm{CDAI} \leq 150)$, it was possible to verify a clinical response at week 6 of $37 \%$ for CZP and $26 \%$ for placebo $(\mathrm{p}<0.05)$. The response at two weeks 6 and 26 (composite outcome) was observed in $22 \%$ of patients receiving CZP and in $12 \%$ of placebo patients ( $p$ $=0.05)$. CZP was superior to placebo in inducing clinical remission at week 4 and at week 26 ( $p<0.05$ for both comparisons), but not at other times evaluated. CZP induction and maintenance therapy was associated with a modest improvement in response rates compared to placebo, but without significant improvement in remission rates. The recurrence rate of adverse events was similar between the groups, with headache, nasopharyngitis and abdominal pain being the most prevalent among patients treated with CZP $(18 \%, 13 \% \text { and } 11 \% \text {, respectively })^{26}(\mathbf{A})$.

Certolizumab pegol in remission maintenance The randomized, double-blind, placebo-controlled PRECiSE 2 study evaluated the efficacy of maintenance therapy for CZP in adults with active Crohn's disease for at least 3 months with moderate to severe activity (CDAI from 220 to 450). As an induction therapy, $400 \mathrm{mg}$ CZP were administered subcutaneously at weeks 0,2 and 4. Patients with clinical response, defined as a reduction of at least 100 points from baseline CDAI at week 6 , were stratified according to their initial C-reactive protein level and randomized to receive $400 \mathrm{mg}$ CZP or placebo every 4 weeks up to the $24^{\text {th }}$ week with follow-up up to week 26 . Among patients responding to induction therapy at week 6 , remission (defined as CDAI $\leq 150$ ) at week 26 was achieved in $48 \%$ of patients in the certolizumab 
group and 29\% in the placebo group (CZP vs. placebo ARA $=19.3 \%$ with $95 \%$ CI -0.285 to -0.097 and NNT $=$ $5, p<0.001)$. The response was maintained at week 26 in $63 \%$ of patients (intention-to-treat analysis) who were receiving CZP versus 36\% receiving placebo (p $<0.001$ ). Serious infectious adverse events, including one case of pulmonary tuberculosis, occurred in $3 \%$ of patients receiving CZP and in less than $1 \%$ of patients receiving placebo ${ }^{27}(\mathrm{~A})$.

Patients who completed PRECiSE 2 were eligible to enter PRECiSE 3, an extension of PRECiSE 2, a prospective and open study, in which patients received CZP (400 mg) every 4 weeks for 54 weeks, with no option being offered increase your dose. A total of 141 of 215 patients who received CZP and 100 of 210 patients who received placebo were eligible for this study. This study aimed to analyze the results of continuous treatment with CZP compared to discontinuation of treatment after drug induction therapy. Disease activity was measured by the Harvey-Bradshaw index ${ }^{27}(\mathbf{A})$.

The response rate verified by the Harvey-Bradshaw index at the $26^{\text {th }}$ week of PRECiSE 2, corresponding to week 0 of the PRECiSE 3 study, was $56.3 \%$ (121 of 215 patients) for patients in the continuous therapy group and $37.6 \%$ (79 of 210 patients) in the group of patients who discontinued $\mathrm{CZP}^{27}(\mathrm{~A})$. Although the reduction in response was evident over time in the continuous therapy and discontinuation groups, substantial response rates were sustained in both groups, being 62.8 and $47.1 \%$ for the $52^{\text {nd }}$ and $80^{\text {th }}$ weeks respectively, between individuals treated continuously. The corresponding values for the discontinued group were 63.3 and $45.6 \%$, respective$\operatorname{ly}^{27}(\mathbf{A})$. CZP was well tolerated in this study and the incidence of AEs was similar both in the continuous group and in the discontinuation of the drug ${ }^{29}(\mathbf{B})$.

An additional dose or re-induction with CZP may help achieve clinical response at 12 months in patients who have not responded previously. This is the conclusion of the PRECiSE 4 study, based on an extension of the PRECiSE 2 study. 124 patients who relapse before week 26 in the original study participated in this study. A total of 49 patients in the PRECISE 2 continuous therapy group received 1 additional dose of CZP $400 \mathrm{mg}$ followed by maintenance with CZP 400 mg every 4 weeks. Another 75 patients in the PRECISE 2 placebo group received CZP $400 \mathrm{mg}$ at weeks 0,2 and 4 , followed by maintenance with CZP 400 mg every 4 weeks. Fifty-five patients (44\%) were withdrawn from the study for 52 weeks, mainly due to AEs, lack of improvement or worsening of the disease. Comparing the continuous and re-induction groups at week 4 , there was a response rate of $63 \%$ vs. $65 \%$, respectively, and in 1 year this result was 55 vs. $59 \%{ }^{30}(\mathbf{B})$.

The multicenter WELCOME study aimed to evaluate the clinical efficacy of CZP in patients with moderate to severe CD (CDAI 220-450), who had lost response or became intolerant to IFX (secondary failures $)^{31}(\mathbf{B})$.

In this study, all patients received induction with CZP 400 mg at weeks 0, 2 and 4, and were then evaluated at week 6 . Only subjects who presented clinical response (CDAI drop $\geq 100$ points) were randomized to maintenance treatment with CZP $400 \mathrm{mg}$ every two or four weeks (329 of 539 patients, 61\%) by the $24^{\text {th }}$ week, and then evaluated in the $26^{\text {th }}$ week. The study was completed in 150 patients (46\%) - a high dropout rate. Comparing CZP every 2 weeks versus every 4 weeks resulted: clinical response of $37 \%$ vs. $40 \%$ (not significant) and clinical remission of $30 \%$ vs. $29 \%$ (not significant) ${ }^{31}(\mathbf{B})$.

\section{Certolizumab pegol in fistulizing CD}

In the PRECISE 1 study, 107 patients had fistulas with drainage at baseline; at week $26,30 \%$ of the CZP group and $31 \%$ of the placebo-treated patients achieved remission of fistula ${ }^{26}(\mathbf{A})$.

A subgroup analysis of the PRECiSE 2 study, including patients with drainage fistulas who responded to treatment after induction therapy, were then randomized to CZP $400 \mathrm{mg}(\mathrm{n}=28)$ or placebo $(\mathrm{n}=$ 30) every 4 weeks, demonstrated that $36 \%$ of patients in the CZP group had complete closure of the fistula at week 26 , compared with $17 \%$ of patients receiving placebo $(p=0.038$; NNT $=5)$. However, partial closure of the fistula ( $\geq 50 \%$ closure at two consecutive visits after the baseline, $\geq 3$ weeks apart) was not statistically different $(p=0.069)$ with $54 \%$ and $43 \%$ of patients treated with CZP and placebo, respectively, at 26 weeks. Therefore, CZP increases the rate of fistula closure by up to 26 weeks in patients with CD who have responded to 6-week induction therapy ${ }^{27}(\mathbf{B})$.

\section{RECOMMENDATIONS}

\section{Adverse effects of anti-TNF- $\alpha$ therapy}

Maintenance therapy with anti-TNF- $\alpha$ is not associated with an increased overall rate of severe infection in the central studies. However, opportunistic 
infections, such as tuberculosis or fungal infections, can occur as a direct consequence of the use of these drugs. Failure to observe an increased rate of these infections in the trials may be secondary to the relatively short follow-up period ${ }^{32}(\mathbf{A})$.

A systematic review with meta-analysis included 22 RCTs comparing anti-TNF $\alpha$ versus placebo in 7,054 patients with inflammatory bowel disease and showed that anti-TNF $\alpha$ therapy doubled the risk of opportunistic infections in patients with inflammatory bowel diseases $(\mathrm{RR}=2.05,95 \% \mathrm{CI}, 1.10-3.85$, NNH $=500$, IC 95\% 200 - 1567). However, including only patients with $\mathrm{CD}$, in the analysis of 15 studies with a total of 4,566 patients, this increase did not show statistical significance $(\mathrm{RR}=2.34,95 \% \mathrm{CI} 0.98$ to $5.57, \mathrm{NNH}=\mathrm{NS})^{32}(\mathbf{A})$.

Another systematic review with 8 historical cohort studies compared IFX therapy up to 3 months after abdominal surgery versus no treatment in 1,641 patients with CD. Comparing preoperative IFX versus non-treatment, IFX therapy was associated with a moderately increased risk of infectious complications (6 studies, $\mathrm{N}=1,159$, OR $=1.50,95 \%$ CI 1.08 $2.08, \mathrm{NNH}=6-41)$, mainly distant from the surgical site $(\mathrm{OR}=2.07,95 \% \mathrm{CI}, 1.30-3.30)$. There was no difference in the rate of noninfectious complications in the analysis of 4 studies with a total of 834 patients $^{33}(\mathrm{~A})$.

Anti-TNF- $\alpha$ therapy may be associated with a small or non-increased risk of neoplasia (melanoma) compared to the general population, but the risk may be increased when in combination with immunomodulatory therapy (thiopurines or methotrexate) $)^{35}(\mathrm{~A})$.

A systematic review with meta-analysis (6 RCTs - CLASSIC I and II, CHARM, GAIN, EXTEND and ADHERE), including data from 1,594 patients (3,050 patients per year of exposure) with CD, compared ADA with immunomodulator versus ADA monotherapy to assess the risk of malignancy. Immunomodulators were defined as any immunomodulator (thiopurine or methotrexate), or thiopurine alone. Comparing ADA monotherapy versus expected incidence in the general population, there was no significant difference in the incidence of non-melanoma skin cancer or other cancers. Combination therapy was associated with increased incidence of non-melanoma skin cancer (standardized incidence rate 3.04, 95\% CI 1.66-5.1) and increased incidence of other malignancies (standardized incidence rate [SIR] 4.59, 95\% CI, 2.51-7.7), in comparison with the general population.
ADA in combination therapy was also associated with increased risk of non-melanoma skin cancer $(\mathrm{RR}=$ 3.46, 95\% CI 1.08-11.06, for combination therapy vs. any immunomodulator and RR corrected $=4.01 ; 95 \%$ CI 1.24-13 for combination therapy vs. thiopurine alone) and increased risk of other neoplasms (RR corrected $=2.82 ; 95 \%$ CI: $1.07-7.44$, for combination therapy vs. any immunomodulator; corrected RR = 2.61; 95\% CI 0.93-7.31 [not significant], for combination therapy vs. thiopurine alone $)^{34}(\mathbf{A})$.

A systematic review with meta-analysis (9 RCTs, 3 cohorts and 14 case series) evaluated the rate of non-Hodgkin's lymphoma (NHL) in adult patients with CD who received anti-TNF therapy. A comparison was done with rates from population registry and a population of CD patients treated with immunomodulators $(8,905$ patients with 21,178 patient/ year of follow-up). Of the 26 studies included, 22 referred to IFX therapy, 3 with ADA and 1 with CZP and an average of $66 \%$ of patients were on concomitant use of immunomodulators. Thirteen NHL cases (6.1 per 10,000 patient-years) were reported among those using TNF inhibitors and most had previous exposure to the immunomodulator (6-MP or AZA) ${ }^{35}(\mathrm{~A})$.

Compared with the expected rate of NHL in the Surveillance Epidemiology and End Results (SEER) database, [1.9 per 10,000 patient-years], TNF inhibitors were associated with increased risk of NHL (SIR $=3.23,95 \%$ CI 1.5-6.9). Compared with the NHL rate in patients treated with isolated immunomodulators (4 per 10,000 patient-years), TNF- $\alpha$ inhibitors were not associated with increased risk of NHL (SIR $=1.7$, 95\% CI 0.5-7.1). There was significant heterogeneity in the NHL rate in all studies. Therefore, the use of anti-TNF- $\alpha$ agents with immunomodulators is associated with an increased risk of NHL in adult patients with $\mathrm{CD}$, but the absolute rate of these events is $\operatorname{low}^{35}(\mathbf{A})$.

A historical cohort study compared 4,554 patients with inflammatory bowel disease (IBD) exposed to TNF- $\alpha$ inhibitors with 16,429 unexposed patients with IBD, in a follow-up of 5 years. TNF- $\alpha$ inhibitors have been associated with increased risk of central demyelinating disease (including multiple sclerosis, optic neuritis, transverse myelitis and other central demyelinating diseases) in patients with inflammatory bowel disease (hazard ratio 2.19, 95\% CI 1.02$4.71)^{36}(\mathbf{A})$.

A systematic review of 5 cohort studies (2 retrospective and 3 prospective) evaluated the use of an- 
ti-TNF- $\alpha$ during pregnancy and the risk of adverse outcome in 1,216 women with IBD (409 pregnancies exposed to anti-TNF agents and 832 non-exposed). Inconsistencies between studies included time, duration, dosage, and varied or unspecified frequency of exposure to anti-TNF- $\alpha$ therapy. ${ }^{37}(\mathbf{B})$.

No significant differences were found regarding the outcomes: abortion rate in the analysis of 5 studies with 1,242 pregnancies; preterm birth in the analysis of 4 studies with 1,055 pregnancies; low birth weight in the analysis of 3 studies with 943 pregnancies; congenital malformation in the analysis of 5 studies with 1,216 pregnancies. Therefore, exposure to tumor necrosis factor inhibitor during pregnancy may not be associated with unfavorable outcomes of pregnancy in women with inflammatory bowel dis$\operatorname{ease}^{37}(\mathbf{B})$.

\section{Certolizumab}

It is effective in inducing and maintaining remission of Crohn's disease in patients with moderate to severe activity refractory to conventional therapy (A).

May have clinical benefits when used in patients with moderate to severe Crohn's disease with failure or intolerance to infliximab (B).

\section{RECOMMENDATIONS}

Biological therapy with anti-integrin antibodies (vedolizumab)

Vedolizumab (VDZ) is a recombinant humanized monoclonal antibody that specifically recognizes $\alpha 4 \beta 7$ integrin present on the surface of lymphocytes, inhibiting the migration of these cells from the bloodstream to the intestinal mucosa through the vascular endothelium. Its mechanism of action promotes selective immunosuppression for the gastrointestinal tract.

GEMINI II ${ }^{38}(\mathbf{B})$ and III RCTs are phase-III multicenter, double-blind, placebo-controlled, non-described allocation concealment trials to assess the efficacy and safety of VDZ in moderate to severe CD, including patients who do not presented previous therapy with anti-TNF $\alpha$ and patients who had an inadequate response, loss of response or intolerance to immunomodulatory or anti-TNF- $\alpha$ agents.

GEMINI II ${ }^{38}$ (B) was designed to evaluate the efficacy and safety of VDZ as an induction treatment (dose at weeks 0 and 2 with evaluation at week 6 ) and maintenance treatment (at weeks 6-52). In contrast,
GEMINI III was designed to evaluate the efficacy and safety of VDZ as an induction treatment only at doses at weeks 0,2 and 6 and at weeks 6 and 10 .

The GEMINI II ${ }^{38}(\mathbf{B})$ study had two cohorts. Cohort 1 was randomized to the induction trial, while cohort 2 received open induction and was randomized to maintenance assessment. Cohort 1 received VDZ $300 \mathrm{mg}$ or placebo, respectively, at week 0 and 2 , and cohort 2 received $300 \mathrm{mg}$ VDZ openly at week 0 and week 2 . Response to therapy was evaluated at week 6 . Responders of treatment arm in both cohorts were randomized to VDZ 300 mg every 8 weeks, VDZ $300 \mathrm{mg}$ every 4 weeks or placebo. Non-responders of the treatment arm received VDZ every 4 weeks. The placebo arm of the induction experiment received placebo during the maintenance phase.

\section{Vedolizumab in remission induction}

In this study it was included 368 patients (mean age 37 years) with active $C D$ for $\geq 3$ months were included (CDAI index 220-450). All patients had no response or had unacceptable side effects with glucocorticoids, immunosuppressive agents or tumor necrosis factor antagonists. The remission defined as CDAI score $\leq 150$ and CDAI-100 response defined as reduction $\geq 100$ points in the CDAI score (CDAI of 0-600). At week 6, comparing VDZ versus placebo, the remission rate was $14.5 \%$ vs. $6.8 \%$, respectively $(p=0.02, \mathrm{NNT}=13)$ and the CDAI-100 response of $31.4 \%$ vs. $25.7 \%$, respectively (not significant). In cohort 2, 747 patients who received open label VDZ had remission in $17.7 \%$ and CDAI-100 response in $34.4 \%$. There was no statistically significant difference in the rate of clinical remission in patients with anti-TNF- $\alpha$ therapy failure with $4.3 \%$ of the placebo group compared to $10.5 \%$ in the VDZ group (ARA 6.2\%, 95\% CI: -1.4-13.7, $\mathrm{p}=0.11$ ). In addition, the CDAI-100 response in patients with anti-TNF- $\alpha$ failure did not reach a statistically significant difference with $22.9 \%$ of the placebo group compared to $23.8 \%$ of the VDZ group (ARA 1.0\%; \%: -11.8-13.7, $\mathrm{p}=0.88$ ). Therefore, induction therapy with VDZ may increase the remission rate in patients with $\mathrm{CD}^{38}(\mathbf{B})$.

\section{Vedolizumab in remission maintenance}

A total of 119 patients from the induction (randomized) phase described above and 674 patients from the cohort with open-label therapy (high study abandonment rate), who presented a response (re- 
duction $\geq 70$ points in the CDAI score) for VDZ at 6 weeks were randomized to VDZ $300 \mathrm{mg}$ IV once every 8 weeks or every 4 weeks versus placebo for 1 year. Treatment was discontinued by $52 \%$ of patients (mainly due to lack of efficacy), but all were included in the intention-to-treat analysis.

The remission rates at 52 weeks were: $39 \%$ with VDZ once every 8 weeks ( $p<0.001$ versus placebo, $\mathrm{NNT}=6) ; 36.4 \%$ with VDZ once every 4 weeks $(\mathrm{p}=$ 0.004 versus placebo, NNT $=7$ ) and $21.6 \%$ with pla$\operatorname{cebo}^{38}(\mathrm{~B})$

CDAI-100 response rates at 52 weeks were: $43.5 \%$ with VDZ once every 8 weeks $(p=0.01$ versus placebo, NNT $=8$ ); $45.5 \%$ with VDZ once every 4 weeks $(p=0.005$ versus placebo, NNT $=7)$ and $30.1 \%$ with placebo $^{38}(\mathrm{~B})$.

The clinical remission rate was statistically significant in patients with anti-TNF- $\alpha$ therapeutic failure with $12.8 \%$ of the placebo group compared to $28.0 \%$ in the VDZ in each 8-week group (ARA 15.2\%; 95\% CI: 3.0-27.5, $\mathrm{p}=0.01$ ) and $27.3 \%$ in the VDZ group every 4 weeks (ARA 14.5\%, 95\% CI 2.0-26.9, $\mathrm{p}=0.02)^{38}(\mathrm{~B})$.

There was no significant difference between groups in durable remission (remission in $\geq 80 \%$ of study visits, including final visit ${ }^{38}(\mathrm{~B})$.

The most common adverse events with VDZ included nasopharyngitis, infections, and severe infections (no p-value reported) ${ }^{38}(\mathrm{~B})$. Therefore, maintenance therapy with VDZ may improve symptoms in patients with previous response to VDZ induction.

GEMINI III RCT is a multicenter, double-blind, placebo-controlled study of VDZ induction therapy for patients with CD (CDAI 220-400) and previous anti-TNF- $\alpha$ therapy failure (which means, an inadequate response, loss of response or intolerance to $\geq 1$ anti-TNF- $\alpha)$. Patients $(\mathrm{N}=315)$ were randomized 1: 1 for induction with VDZ $300 \mathrm{mg}$ IV at week 0, 2 and 6 or placebo. The primary outcome was clinical remission at week 6 . Secondary outcomes were clinical remission at week 6 in the general population $(\mathrm{N}=416$; patients with anti-TNF- $\alpha$ failure $[\mathrm{N}=315]$ plus those without prior anti- TNF- $\alpha$ [N = 101], clinical remission at week 10 also in both populations, long-term clinical remission (defined as remission at weeks 6 and 10 in both populations) and CDAI-10O response at week 6 in patients failing prior to anti-TNF- $\alpha$. This study showed no difference with statistical significance for the primary outcome. However, the secondary outcome, clinical remission in the general population (anti-TNF $\alpha$ failure + virgin; $N=416$ ) at week 6 , reached statistical significance with $26.6 \%$ in the VDZ group, compared with $12.1 \%$ in the placebo group $(p=0.001)^{39}(B)$. At week 10, a greater proportion of patients with prior fail to anti-TNF- $\alpha$ therapy who received VDZ was in remission (26.6\%) compared to those receiving placebo $(12.1 \%)(p=0.001$, $\mathrm{RR}=2.2,95 \% \mathrm{CI}, 1.3-3.6)$. There was also a higher rate of patients with prior fail to anti-TNF- $\alpha$ therapy who received VDZ with CDAI-100 response at week 6 compared to those receiving placebo (39.2\% vs.22.3\%, $\mathrm{p}=0.001 ; \mathrm{RR}=1.8 ; 95 \%$ CI 1.2-2.5 ${ }^{39}(\mathrm{~B})$.

VDZ is effective at clinical remission at week 10, but not at week 6 , in moderate to severe $\mathrm{CD}$ in patients failing anti-TNF- $\alpha$ therapy. VDZ is effective in clinical response (CDAI-100) at weeks 6 and 10 in moderate to severe CD in patients failing anti-TNF- $\alpha$ therapy. Better results can be obtained in patients without previous use of anti-TNF- $\alpha$. The rate of adverse events was similar among all groups ${ }^{39}(\mathrm{~B})$.

Post hoc analyzes of efficacy data for 516 patients without prior anti-TNFa use and 960 anti-TNFa failure patients from the GEMINI 2 and GEMINI 3 trials were done at weeks 6,10 and 52 . Clinical remission ( $\mathrm{CDA} \leq 150)$, clinical response (reduction $\geq 100$ points in CDAI), long-term clinical remission (remission in $\geq 80 \%$ of study visits, including final visit) and remission without corticosteroids outcomes were evaluated. Among patients responding to VDZ induction at week $6,48.9 \%$ of patients without prior anti-TNF- $\alpha$ use and $27.7 \%$ of anti-TNF- $\alpha$ failure patients were in remission with VDZ at week 52 (versus $26.8 \%$ and $12.8 \%$ with placebo, $\mathrm{p}<0.05$ for all comparisons). The clinical efficacy was similar in relation to the number or type of anti-TNF- $\alpha$ previously used. The safety profiles were similar in both subpopulations ${ }^{40}(\mathrm{~B})$.

Patients in the C13004 (phase II), GEMINI 2 and GEMINI 3 (both phase III) studies and VDZ virgin patients were included in the GEMINI LTS study ${ }^{41}(\mathrm{C})$ (GEMINI long-term safety [LTS]), an extension, open-label, phase III and single-arm study, whose main objective was to evaluate the safety profile of VDZ $300 \mathrm{mg}$ IV treatment every 4 weeks in the long term. Clinical response and remission results, as defined by the Harvey-Bradshaw Index (scores ranging from 0 to $\geq 18$ with higher scores indicating increased disease activity) and health-related quality of life (HRQL) were assessed for up to 152 weeks of treatment ${ }^{41}(C)$. Interim data for up to 100 weeks of treatment with VDZ in GEMINI LTS will be reported 
here with a total follow-up of approximately 3 years (152 weeks of exposure) for patients who completed the 52-week GEMINI 2 study ${ }^{41}(\mathrm{C})$.

Among patients with response at week 6 in GEMINI 2 who received continuous VDZ, 83\% (n = $100 / 120)$ and $89 \%(n=62 / 70)$ of the patients, with available data (as observed analysis), were in remission after 104 and 152 weeks, respectively. The increase in dose frequency of every 8 (GEMINI 2) for every 4 weeks (GEMINI LTS) improved the results in patients who had been withdrawn from GEMINI 2 in advance, with $47 \%$ of them $(n=27 / 57)$ with clinical response and $32 \%(n=18 / 57)$ in remission in week 52 of GEMINI LTS. Previous exposure of patients to anti-TNF- $\alpha$ did not alter the benefits found. The long-term benefits of HRQL were also observed $^{41}(\mathrm{C})$.

It is concluded that the clinical benefits of VDZ continued with long-term treatment regardless of previous exposure to anti-TNF; and increasing the frequency of the dose used (every 4 weeks) may improve outcomes in patients who lose response or remission at the conventional dose every 8 weeks ${ }^{41}(C)$.

\section{Vedolizumab in fistulizing CD}

A subgroup analysis of the GEMINI 2 study evaluated the closure of fistulas in patients with baseline drainage fistulas up to week 52 . There was an increase in the number of non-draining fistulas with the use of VDZ every 8 weeks in the placebo comparison in 52 weeks ( $41.2 \%$ vs. $11.1 \%$, respectively - ARA = $30.1 \%, 95 \%$ CI $2.6-57.6 \%$, NNT $=3,95 \%$ CI $2-39$ ). The power of this study (subgroup analysis) to detect a $30 \%$ difference between the placebo and VDZ groups, every 8 weeks, with a level of significance of $5 \%(95 \% \mathrm{CI})$, is only $53.2 \%$. There was no difference between the VDZ group every 4 weeks and placebo $(\mathrm{NNT}=\mathrm{NS})^{38}(\mathbf{B})$.

\section{Adverse effects with the use of Vedolizumab}

Data from 2,932 patients with ulcerative colitis or CD of 4 RCTs and 2 extension studies comparing VDZ vs. placebo were analyzed based on the individual data of the patients, without evaluation of the quality of the studies. The rate of serious adverse events in patients with CD was: 25.1 events per 100 person-years (CI 95\%: 22.9-27.4) with VDZ in the analysis of 1,723 patients from 4 trials and 31.8 events per 100 person-years (95\% CI 21.5-42) with placebo in the analysis of 355 patients from 2 trials. The rate of severe infection or infestation was: 5.6 events per
100 person-years (95\% CI: 4.6-6.5) with VDZ in the analysis of 1,723 patients from 4 trials and 3 events per 100 person-years (95\% CI: 0.1-6) with placebo in the analysis of 355 patients from 2 trials. Concluding this study that VDZ may not increase the risk of serious adverse events or infection in patients with $\mathrm{CD}^{42}(\mathrm{~B})$.

\section{RECOMMENDATIONS}

Vedolizumab

It is effective in inducing and maintaining remission of Crohn's disease in patients with moderate to severe activity refractory to conventional therapy and/or failed therapy with anti-TNF $\alpha$ biological agents (B).

It may be effective in perianal fistulizing $\mathrm{CD}(\mathrm{B})$.

\section{Anti-interleukin antibodies (Ustekinumab)}

Ustekinumab (UTQ) is a human monoclonal antibody directed against IL-12 and IL-23, two important pro-inflammatory cytokines in the pathophysiology of CD.

\section{UsteKinumab in remission induction}

A systematic review with meta-analysis including 6 RCTs evaluated the efficacy and safety of anti-interleukin-12/23p40 monoclonal antibodies (including UTQ) in 2,324 patients with moderate to severe active CD. Four RCTs evaluated the UTQ (UNITI-1, UNITI-2, CERTIFI and Sandborn WJ 2008). The clinical response outcomes defined as $\geq 100$ points of improvement in the CDAI score and clinical remission defined as CDAI score $<150$ points were assessed. Comparing the UTQ $1-6 \mathrm{mg} / \mathrm{kg}$ IV versus placebo, UTQ reduced the risk of failure to induce clinical response, up to 6 weeks, in the analysis of 4 RCTs with 1,947 patients $(\mathrm{RR}=0.77,95 \%$ CI 0.69 to 0.87 , NNT 5-11, failure to induce clinical response of $76 \%$ in the placebo group); as well as reduced the risk of failure to induce clinical remission up to 6 weeks in the analysis of 4 RCTs with 1,947 patients, but with a confidence interval including a difference that may not be clinically important $(\mathrm{RR}=0.91,95 \% \mathrm{CI} 0.86$ to 0.95 , NNT $=9-23$, with failure to induce remission in $88 \%$ in the placebo group $)^{43}(\mathbf{A})$.

There was no difference in the number of serious adverse events between the two groups in the analysis of 4 RCTs with a total of 2,023 patients.

Therefore, UTQ increases clinical response and 
may increase clinical remission in patients with active, moderate to severe Crohn's disease ${ }^{43}(\mathrm{~A})$.

\section{Ustekinumab in remission maintenance with UTQ}

An RCT (IM-UNITI trial) included 397 adult patients (mean age 43 years) with moderate to severe CD who presented clinical response to UTQ induction therapy at 8 weeks in UNITI-1 and UNITI-2 RCTs. Patients were randomized to 1 of 3 subcutaneous maintenance regimens with UTQ for 40 weeks and followed up to week 44: UTQ $90 \mathrm{mg}$ every 8 weeks, UTQ $90 \mathrm{mg}$ every 12 weeks or placebo. Blinding was maintained by administering treatments every 4 weeks and using placebo between the active treatments. Patients meeting the response loss criteria (CDAI $\geq 220$ and $\geq 100$ baseline increase points) at weeks 8 - 32 received $90 \mathrm{mg}$ UTQ every 8 weeks. $2.3 \%$ of the patients were excluded from the analyzes, due to administration of the initial formulation of the drug with stability problems. The response and clinical remission outcomes were described in RS with meta-analysis described above. The clinical response rates at week 44 were: $59.4 \%$ with UTQ every 8 weeks ( $p=0.02$ vs. placebo, NNT 7); $58.1 \%$ with UTQ every 12 weeks ( $p=0.03$ vs. placebo, NNT 8$)$ and $44.3 \%$ with placebo. Clinical remission rates at week 44 were: $53.1 \%$ with UTQ every 8 weeks ( $p=0.005$ versus placebo, NNT 6); 48.8\% with UTQ every 12 weeks ( $p=0.04$ versus placebo, NNT 8) and $35.9 \%$ with placebo. Adverse events rates were similar between the treatment groups (80.3\% - 83.5\%), with the most common adverse events being infections, arthralgia, headache, nasopharyngitis, abdominal pain and fever ${ }^{44}(\mathbf{A})$.

Another RCT (CERTIFI Study) including 526 pa- tients (mean age 39 years) with moderate to severe CD randomized to induction therapy with UTQ IV (1 $\mathrm{mg} / \mathrm{kg}$ vs. $3 \mathrm{mg} / \mathrm{kg}$ vs. $6 \mathrm{mg} / \mathrm{kg}$ ) versus placebo for 8 weeks. Mean baseline CDAI values were significantly lower in the placebo and UTQ $1 \mathrm{mg}$ groups compared to the higher dose UTQ groups ${ }^{45}(\mathrm{~A})$.

A group of 145 patients, all failing treatment with a baseline tumor necrosis factor antagonist and who had a clinical response to UTQ at week 6 , were randomized again to subcutaneous injections of UTQ 90 mg versus placebo in the weeks 8 and 16 as maintenance therapy. The clinical response was defined as a decrease $\geq 100$ points in the CDAI score and clinical remission as $\mathrm{CDAI}<150^{45}(\mathrm{~A})$.

Comparing UTQ $90 \mathrm{mg}$ vs. placebo, as maintenance therapy, at week 22 , the UTQ increased clinical response rates $(69.4 \%$ vs. $42.5 \%, \mathrm{p}<0.001$; NNT 38 ), sustained response defined as clinical response at each visit during the $(55.6 \%$ vs. $32.9 \%, p=0.005$, NNT 5) and clinical remission $(41.7 \%$ vs. $27.4 \%, p=$ 0.03 and NNT 7). It is concluded that maintenance therapy with UTQ can improve clinical response and remission at week 22 in patients with moderate to severe Crohn's disease non responsive toanti TNF antagonists to tumor necrosis factor antagonists who had initial response to $\mathrm{UTQ}^{45}(\mathbf{A})$.

\section{RECOMMENDATIONS}

Ustekinumab is effective in inducing and maintaining remission of Crohn's disease in patients with moderate to severe activity refractory to conventional therapy, including patients failing prior to anti-TNF- $\alpha$ therapy (A).

\section{REFERENCES}

1. Targan SR, Hanauer SB, van Deventer SJ, Mayer L, Present DH, Braakman $T$, et al. A short-term study of chimeric monoclonal antibody $\mathrm{CA} 2$ to tumor necrosis factor alpha for Crohn's disease. Crohn's Disease cA2 Study Group. N Engl J Med 1997;337:1029-35. PMID: 9321530

2. Present DH, Rutgeerts $P$, Targan $S$, Hanauer SB, Mayer L, van Hogezand $R A$, et al. Infliximab for the treatment of fistulas in patients with Crohn's disease. N Engl J Med 1999;340:1398-405. PMID: 10228190

3. Rutgeerts P, Geboes K, Vantrappen G, Beyls J, Kerremans R, Hiele M. Predictability of the postoperative course of Crohn's disease. Gastroenterology. 1990;99:956-63. PMID: 2394349

4. Hanauer SB, Feagan BG, Lichtenstein GR, Mayer LF, Schreiber S, Colombel JF, et al. Maintenance infliximab for Crohn's disease: the ACCENT I randomised trial. Lancet 2002;359:1541-9. PMID: 12047962

5. Sands BE, Anderson FH, Bernstein CN, Chey WY, Feagan BG, Fedorak $\mathrm{RN}$, et al. Infliximab maintenance therapy for fistulizing Crohn's disease. N Engl | Med 2004;350:876-85. PMID: 14985485

6. Colombel JF, Reinisch W, Mantzaris GJ, Kornbluth A, Rutgeerts P, Tang $\mathrm{KL}$, et al. Randomised clinical trial: deep remission in biologic and im-

munomodulator naïve patients with Crohn's disease - a SONIC post hoc analysis. Aliment Pharmacol Ther 2015;41:734-46. PMID: 25728587

7. Colombel JF, Sandborn WJ, Reinisch W, Mantzaris GJ, Kornbluth A, Rachmilewitz D, et al. Infliximab, azathioprine, or combination therapy for Crohn's disease. N Engl J Med 2010;362:1383-95. PMID: 20393175

8. Hazlewood GS, Rezaie A, Borman M, Panaccione R, Ghosh S, Seow CH, et al. Comparative effectiveness of immunosuppressants and biologics for inducing and maintaining remission in Crohn's disease: a network meta-analysis. Gastroenterology 2015;148:344-54.e5; quiz e14-5. PMID: 25448924

9. Lémann M, Mary JY, Duclos B, Veyrac M, Dupas |L, Delchier |C, et al. Infliximab plus azathioprine for steroid-dependent Crohn's disease patients: a randomized placebo-controlled trial. Gastroenterology 2006;130:105461. PMID: 16618399

10. D'Haens G, Baert F, van Assche G, Caenepeel P, Vergauwe P, Tuynman H, et al. Early combined immunosuppression or conventional management in patients with newly diagnosed Crohn's disease: an open randomised trial. Lancet 2008;371:660-667. PMID: 18295023 
11. Regueiro M, Feagan BG, Zou B, Johanns J, Blank MA, Chevrier M, et al. Infliximab Reduces Endoscopic, but Not Clinical, Recurrence of Crohn's Disease After lleocolonic Resection. Gastroenterology 2016;150:15681578. PMID: 26946343

12. Hanauer SB, Sandborn WJ, Rutgeerts P, Fedorak RN, Lukas M, Maclntosh $D$, et al. Human anti-tumor necrosis factor monoclonal antibody (adalimumab) in Crohn's disease: the CLASSIC-I trial. Gastroenterology 2006;130:323-33; quiz 591. PMID: 16472588

13. Sandborn WJ, Rutgeerts P, Enns R, Hanauer SB, Colombel JF, Panaccione $\mathrm{R}$, et al. Adalimumab induction therapy for Crohn disease previously treated with infliximab: a randomized trial. Ann Intern Med 2007;146:82938. PMID: 17470824

14. Sandborn WI, Hanauer SB, Rutgeerts P, Fedorak RN, Lukas M, Maclntosh DG, Panaccione R, Wolf D, Kent JD, Bittle B, Li J, Pollack PF. Adalimumab for maintenance treatment of Crohn's disease: results of the CLASSIC II trial. Gut 2007;56:1232-9. PMID: 17299059

15. Colombel JF, Sandborn W|, Rutgeerts P, Enns R, Hanauer SB, Panaccione $R$, et al. Adalimumab for maintenance of clinical response and remission in patients with Crohn's disease: the CHARM trial. Gastroenterology 2007;132:52-65. PMID: 17241859

16. Panaccione R, Colombel JF, Sandborn WJ, Rutgeerts P, D'Haens GR, Robinson $A M$, et al. Adalimumab sustains clinical remission and overall clinical benefit after 2 years of therapy for Crohn's disease. Aliment Pharmacol Ther 2010;31:1296-309. PMID: 20298496

17. Panaccione R, Colombel JF, Sandborn WJ, D'Haens G, Zhou Q, Pollack PF, et al. Adalimumab maintains remission of Crohn's disease after up to 4 years of treatment: data from CHARM and ADHERE. Aliment Pharmacol Ther 2013;38:1236-47. PMID: 24134498

18. Rutgeerts P, Van Assche G, Sandborn WJ, Wolf DC, Geboes K, Colombel IF, et al. Adalimumab induces and maintains mucosal healing in patients with Crohn's disease: data from the EXTEND trial. Gastroenterology 2012;142:1102-1111.e2. PMID: 22326435

19. Colombel JF, Schwartz DA, Sandborn WJ, Kamm MA, D'Haens G, Rutgeerts $P$, et al. Adalimumab for the treatment of fistulas in patients with Crohn's disease. Gut 2009;58:940-8. PMID: 19201775

20. Hinojosa I, Gomollón F, García S, Bastida G, Cabriada JL, Saro C, et al. Efficacy and safety of short-term adalimumab treatment in patients with active Crohn's disease who lost response or showed intolerance to infliximab: a prospective, open-label, multicentre trial. Aliment Pharmacol Ther 2007;25:409-18. PMID: 17269996

21. Lichtiger S, Binion DG, Wolf DC, Present DH, Bensimon AG, Wu E, et al. The CHOICE trial: adalimumab demonstrates safety, fistula healing, improved quality of life and increased work productivity in patients with Crohn's disease who failed prior infliximab therapy. Aliment Pharmacol Ther 2010;32:1228-39. PMID: 20955442

22. Matsumoto T, Motoya S, Watanabe K, Hisamatsu T, Nakase H, Yoshimura $\mathrm{N}$, et al. Adalimumab Monotherapy and a Combination with Azathioprine for Crohn's Disease: A Prospective, Randomized Trial. J Crohns Colitis 2016;10:1259-1266. PMID: 27566367

23. Savarino E, Bodini G, Dulbecco P, Assandri L, Bruzzone L, Mazza F, et al. Adalimumab is more effective than azathioprine and mesalamine at preventing postoperative recurrence of Crohn's disease: a randomized controlled trial. Am | Gastroenterol 2013;108:1731-42. PMID: 24019080

24. Sandborn WJ, Feagan BG, Stoinov S, Honiball PJ, Rutgeerts P, Mason D, et al. Certolizumab pegol for the treatment of Crohn's disease. N Engl | Med 2007:357:228-38. PMID: 17634458

25. Schreiber S, Khaliq-Kareemi M, Lawrance IC, Thomsen O $\varnothing$, Hanauer SB McColm J, et al. Maintenance therapy with certolizumab pegol for Crohn's disease. N Engl I Med 2007;357:239-50. PMID: 17634459

26. Sandborn WJ, Schreiber S, Feagan BG, Rutgeerts P, Younes ZH, Bloomfield $R$, et al. Certolizumab pegol for active Crohn's disease: a placebo-controlled, randomized trial. Clin Gastroenterol Hepatol 2011;9:670-678.e3. PMID: 21642014

27. Lichtenstein GR, Thomsen $O \varnothing$, Schreiber S, Lawrance IC, Hanauer SB Bloomfield R, et al. Continuous therapy with certolizumab pegol maintains remission of patients with Crohn's disease for up to 18 months. Clin Gastroenterol Hepatol 2010;8:600-9. PMID: 20117244

28. Sandborn WJ, Schreiber S, Hanauer SB, Colombel JF, Bloomfield R, Lichtenstein GR. Reinduction with certolizumab pegol in patients with relapsed Crohn's disease: results from the PRECiSE 4 Study. Clin Gastroenterol Hepatol 2010;8:696-702.e1. PMID: 20363366
29. Sandborn WJ, Abreu MT, D'Haens G, Colombel JF, Vermeire S, Mitchev $\mathrm{K}$, et al. Certolizumab pegol in patients with moderate to severe Crohn's disease and secondary failure to infliximab. Clin Gastroenterol Hepatol 2010;8:688-695.e2. PMID: 20451663

30. Ford AC, Peyrin-Biroulet L. Opportunistic infections with anti-tumor necrosis factor- $\alpha$ therapy in inflammatory bowel disease: meta-analysis of randomized controlled trials. Am | Gastroenterol 2013;108:1268-76. PMID: 23649185

31. Kopylov U, Ben-Horin S, Zmora O, Eliakim R, Katz LH. Anti-tumor necrosis factor and postoperative complications in Crohn's disease: systematic review and meta-analysis. Inflamm Bowel Dis 2012;18:2404-13. PMID: 22467533

32. Osterman MT, Sandborn WJ, Colombel JF, Robinson AM, Lau W, Huang $B$, et al. Increased risk of malignancy with adalimumab combination therapy, compared with monotherapy, for Crohn's disease. Gastroenterology 2014;146:941-9. PMID: 24361468

33. Siegel CA, Marden SM, Persing SM, Larson RJ, Sands BE. Risk of lymphoma associated with combination anti-tumor necrosis factor and immunomodulator therapy for the treatment of Crohn's disease: a meta-analysis. Clin Gastroenterol Hepatol 2009;7:874-81. PMID: 19558997

34. Nyboe Andersen N, Pasternak B, Andersson M, Nielsen NM, Jess T. Risk of Demyelinating Diseases in the Central Nervous System in Patients With Inflammatory Bowel Disease Treated With Tumor Necrosis Factor Inhibitors. JAMA Intern Med 2015;175:1990-2. PMID: 26437461

35. Narula N, Al-Dabbagh R, Dhillon A, Sands BE, Marshall JK. Anti-TNF $\alpha$ therapies are safe during pregnancy in women with inflammatory bowel disease: a systematic review and meta-analysis. Inflamm Bowel Dis 2014:20:1862-9. PMID: 2498398

36. Sandborn WJ, Feagan BG, Rutgeerts P, Hanauer S, Colombel JF, Sands BE, et al. Vedolizumab as induction and maintenance therapy for Crohn's disease. N Engl | Med 2013;369:711-21. PMID: 23964933

37. Sands BE, Feagan BG, Rutgeerts P, Colombel JF, Sandborn W|, Sy R, D'Haens $G$, et al. Effects of vedolizumab induction therapy for patients with Crohn's disease in whom tumor necrosis factor antagonist treatment failed. Gastroenterology 2014;147:618-627.e3. PMID: 24859203

38. Sands BE, Sandborn WJ, Van Assche G, Lukas M, Xu J, lames A, et al Vedolizumab as Induction and Maintenance Therapy for Crohn's Disease in Patients Naïve to or Who Have Failed Tumor Necrosis Factor Antagonist Therapy. Inflamm Bowel Dis. 2017;23:97-106. PMID: 27930408

39. Vermeire S, Loftus EV Jr, Colombel JF, Feagan BG, Sandborn WJ, Sands BE, et al. Long-term Efficacy of Vedolizumab for Crohn's Disease. J Crohns Colitis 2017 1;11:412-424. PMID: 27683798

40. Colombel JF, Sands BE, Rutgeerts P, Sandborn W, Danese S, D'Haens G, et al. The safety of vedolizumab for ulcerative colitis and Crohn's disease. Gut 2017;66(5):839 851. PMID: 26893500

41. MacDonald IK, Nguyen TM, Khanna R, Timmer A. Anti-IL-12/23p40 antibodies for induction of remission in Crohn's disease. Cochrane Database Syst Rev 2016;11:CD007572. PMID: 27885650

42. Feagan BG, Sandborn WJ, Gasink C, Jacobstein D, Lang Y, Friedman JR, et al. Ustekinumab as Induction and Maintenance Therapy for Crohn's Disease. N Engl | Med 2016;375:1946-1960. PMID: 27959607

43. Sandborn WJ, Gasink C, Gao LL, Blank MA, Johanns J, Guzzo C, et al. Ustekinumab induction and maintenance therapy in refractory Crohn's disease. N Engl J Med. 2012;367:1519-28. PMID: 23075178

44. Shea BJ, Hamel C, Wells GA, Bouter LM, Kristjansson E, Grimshaw J et al. AMSTAR is a reliable and valid measurement tool to assess the methodological quality of systematic reviews. I Clin Epidemiol 2009; 62:1013-20. PMID: 19230606 (http://amstar.ca/Amstar_Checklist.php)

45. Jadad AR, Moore RA, Carroll D, Jenkinson C, Reynolds D|, Gavaghan D|, et al. Assessing the quality of reports of randomized clinical trials: is blinding necessary? Control Clin Trials 1996; 17:1-12.

46. Goldet G, Howick J. Understanding GRADE: an introduction. J Evid Based Med 2013; 6:50-4.

47. Wells G, Shea B, O'Connell D, Robertson J, Peterson J., Welch $V$, et al. The Newcastle-Ottawa Scale (NOS) for assessing the quality of nonrandomised studies in meta-analyses. Disponível em: http://www.ohri.ca/ programs/clinical_epidemiology/oxford.asp.

48. Levels of Evidence and Grades of Recommendations - Oxford Centre for Evidence Based Medicine. Disponível em URL: http://cebm.jr2.ox.ac.uk/ docs/ old_levels. Htm. 